\title{
The effect of processing conditions on the morphology, thermomechanical, dielectric, and piezoelectric properties of $\mathrm{P}(\mathrm{VDF}-\mathrm{TrFE}) / \mathrm{BaTiO}_{3}$ composites
}

\author{
Sara Dalle Vacche $\cdot$ Fabiane Oliveira $\cdot$ \\ Yves Leterrier • Véronique Michaud · \\ Dragan Damjanovic · Jan-Anders E. Månson
}

Received: 10 January 2012/Accepted: 14 February 2012/Published online: 1 March 2012

(C) Springer Science+Business Media, LLC 2012

\begin{abstract}
In this study (0-3) $\mathrm{P}(\mathrm{VDF}-\mathrm{TrFE}) / \mathrm{BaTiO}_{3}$ composites containing up to $60 \mathrm{vol} \%$ of ceramic phase were prepared by solvent casting or compression molding. Their thermomechanical, dielectric, and piezoelectric properties were investigated, and discussed in the light of the properties of the basic components, the processing route and the resulting morphology. The crystalline structure of the $\mathrm{P}(\mathrm{VDF}-\mathrm{TrFE})$ matrix was found to be highly dependent on the processing route, while the structure of $\mathrm{BaTiO}_{3}$ was not affected by any of the processing steps. The mechanical properties of the solvent cast materials showed a maximum at $30 \mathrm{vol} \% \mathrm{BaTiO}_{3}$, while they increased monotonically with $\mathrm{BaTiO}_{3}$ content for compression molded materials. This difference was attributed to a higher amount of porosity and inhomogeneities in the solvent cast composites. Permittivity as high as 120 and piezoelectric coefficient $d_{33}$ up to $32 \mathrm{pC} / \mathrm{N}$ were obtained for compression molded composites, and the observed decrease in $d_{33}$ with aging time was attributed to the effect of mechanical stress release in the polymer matrix.
\end{abstract}

S. D. Vacche · F. Oliveira · Y. Leterrier $(\bowtie) \cdot$ V. Michaud . J.-A. E. Månson

Laboratoire de Technologie des Composites et Polymères (LTC), Ecole Polytechnique Fédérale de Lausanne (EPFL), 1015 Lausanne, Switzerland

e-mail: yves.leterrier@epfl.ch

D. Damjanovic

Ceramics Laboratory (LC), Ecole Polytechnique

Fédérale de Lausanne (EPFL), 1015 Lausanne,

Switzerland

\section{Introduction}

Composites combining a piezoelectric ceramic phase and a polymer phase, either inactive or piezoelectric, have attracted great interest as they offer a unique combination of properties and design flexibility [1,2]. Piezoelectric and pyroelectric activity, a wide range of dielectric constants and high-breakdown strength are combined with mechanical flexibility, formability, and low acoustic impedance. Furthermore the properties of piezoelectric composites may be tailored by the judicious choice of the polymeric matrix and ceramic filler, of their volume fraction, and of the type of connectivity, making these materials very attractive for applications as sensors and actuators. Binary piezoelectric composites may have different connectivity patterns, which were classified by Newnham et al. [3] and designated by the notation $(m-n)$, where $m$ and $n$ indicate the connectivity of each one of the two phases. According to this nomenclature, composites in which piezoelectric ceramic particles are completely surrounded by a threedimensionally connected polymeric phase have (0-3) connectivity. As (0-3) composites are easier to manufacture and shape than composites with other connectivity patterns, a large research effort is taking place to improve their piezoelectric coefficient. Several polymers have been used as matrices for such composites, including, e.g., epoxy resins [4, 5], chloroprene [6], polyethylene oxide [7], and polyamides $[8,9]$. Polyvinylidene fluoride (PVDF) and its copolymer with trifluoroethylene, $\mathrm{P}(\mathrm{VDF}-\mathrm{TrFE})$, have raised particular interest as they have large relative permittivity and high dielectric strength, and exhibit themselves a relatively large piezoelectric activity. It has been demonstrated for this type of composites that it is possible to polarize independently the polymeric matrix and/or the ceramic inclusions [10-13], therefore adding an additional 
degree of freedom to the tuning of the composite properties. Lead containing perovskites, and particularly PZT $\left(\mathrm{Pb}(\mathrm{Zr}, \mathrm{Ti}) \mathrm{O}_{3}\right.$-lead zirconium titanate), are at present the most widely used materials for sensors, actuators, and other electronic devices because of their excellent piezoelectric properties, ease of fabrication, and low cost manufacturing [14]. Hence, most of the studies on piezoelectric ceramicpolymer composites with high-piezoelectric activity deal with PZT-based materials [7, 12, 13, 15-17]. However, for environmental and health concerns it is desirable to substitute PZT with a lead-free piezoelectric ceramic and $\mathrm{BaTiO}_{3}$ may offer a convenient alternative [18]. Although the piezoelectric coefficient $d_{33}$ of conventional $\mathrm{BaTiO}_{3}$ is lower than that of PZT, a large effort is lately taking place in fabricating high-performance $\mathrm{BaTiO}_{3}$ [19]. In addition to this, polymer/BaTiO ${ }_{3}$ composites are also of great interest for the fabrication of high-relative permittivity materials for, e.g., embedded capacitors [20-24]. For polymer $/ \mathrm{BaTiO}_{3}$ composites the reported absolute values for $d_{33}$ are usually between 1 and $30 \mathrm{pC} / \mathrm{N}[6,8,25,26]$ (the sign depending on the polarization conditions in the case of piezoelectric polymer matrices), although a $d_{33}$ higher than $50 \mathrm{pC} / \mathrm{N}$ was reported for a $\mathrm{PVDF} / \mathrm{BaTiO}_{3}$ composite [27].

The functionality of these composite materials is mostly due to the dielectric, ferroelectric, and piezoelectric properties of the ceramic phase, which often needs to constitute more than $50 \%$ in volume. Thus, a challenge is to obtain homogeneous composites with a well-dispersed ceramic phase. Furthermore piezoelectric ceramics, e.g., PZT or $\mathrm{BaTiO}_{3}$, are hydrophilic, and dispersion in highly hydrophobic polymers as PVDF and its copolymers may favor their agglomeration. For example, although mechanical powder mixing has been sometimes used [27], most of the PVDF and P(VDF-TrFE)-based composites reported in literature were prepared by first dispersing the polymer and ceramics in a solvent. Films were then obtained by solvent casting [28, 29], spin coating [30], and/or hot pressing/ compression molding under different conditions [26, 31]. Annealing was also sometimes used to improve crystallinity of the polymeric matrix [32]. Highly filled (0-3) composites, however, present a complex morphology due to the coexistence of several phases: not only the polymer matrix and the ceramic filler particles, but also, at high filler concentrations, filler aggregates, and porosities (at microscopic and macroscopic level), as well as residual solvent may be present depending on the processing routes and conditions. As pointed out in a recent review [33], modification of the surface of the ceramic fillers, through chemical grafting or the production of core-shell structures is key to improve filler dispersion, reduce porosity, thereby improving the mechanical, and electrical properties of the composites. Most of the existent studies focus on the dielectric [34-43] and electromechanical $[4,7,13,15,17$, $25,44]$ properties of such composites and relatively few systematic studies on their thermal and mechanical behavior have been published so far. Furthermore the ceramic volume fractions considered are often much lower than those used in most applications [45], studies of highly filled composites mainly being limited to lead-based ferroelectric materials $[46,47]$. The aim of this study is therefore to study the effect of processing conditions on both the thermomechanical and the dielectric and piezoelectric properties of $\mathrm{P}(\mathrm{VDF}-\mathrm{TrFE}) / \mathrm{BaTiO}_{3}$ composites over a wide range of compositions.

\section{Experimental}

Materials and sample preparation

$\mathrm{P}$ (VDF-TrFE) $(77 / 23 \mathrm{~mol} \%)$ in powder form was provided by Solvay Solexis SpA (Italy). Two $\mathrm{BaTiO}_{3}$ powders were used as piezoelectric ceramic fillers. The first one (BT-1) was a commercial powder (Barium titanate (IV), $<2 \mu \mathrm{m}$, 99.9\% from Sigma Aldrich, USA). The second one (BT-2) was an in house made $\mathrm{BaTiO}_{3}$ powder, obtained by milling $\mathrm{BaCO}_{3}$ and $\mathrm{TiO}_{2}$ powders in stoichiometric ratio, performing calcination at $1100{ }^{\circ} \mathrm{C}$ for $3 \mathrm{~h}$ and milling again until the desired particle size was achieved. Methyl ethyl ketone (MEK) was used as solvent (Acros Organics, 2-butanone, $99+\%)$.

Solvent cast films were obtained by first dissolving $\mathrm{P}(\mathrm{VDF}-\mathrm{TrFE})$ in MEK at $60{ }^{\circ} \mathrm{C}$ in an oil bath on a magnetic stirrer for several minutes, until complete dissolution of the polymer. Then $\mathrm{BaTiO}_{3}$ was added slowly to the stirred solution in order to avoid powder sedimentation or agglomeration. The solution was then placed in an ultrasound bath (Sonorex Super, Bandelin GmbH \& Co. KG, Germany) for $1 \mathrm{~h}$ to further disagglomerate the powder $[26,31]$. Finally the solution was cast on glass and the solvent was evaporated at room temperature in vacuum for $12 \mathrm{~h}$, and then at $70{ }^{\circ} \mathrm{C}$ in vacuum for $2 \mathrm{~h}$. The films obtained in this way were then divided in three sets. One set was tested without further treatment, one set was annealed at $135{ }^{\circ} \mathrm{C}$ for $30 \mathrm{~min}$ prior to testing, and one set was used to produce compression molded films. Compression molding was performed in a TP50 hydraulic press (Fontijne Holland, Netherlands). Two layers of solvent cast films were superposed and then pressed with $5 \mathrm{MPa}$, while heating from 25 to $200{ }^{\circ} \mathrm{C}$ in $20 \mathrm{~min}$, then holding at $200{ }^{\circ} \mathrm{C}$ for $10 \mathrm{~min}$, and cooling to $25^{\circ} \mathrm{C}$ in $20 \mathrm{~min}$. Materials containing $15,30,45$, and $60 \mathrm{vol} \%$ of BT- 1 powder, and 60 vol\% of BT-2 powder were prepared. A concentration of $60 \mathrm{vol} \%$ was the limit for which solvent cast films did not disintegrate upon removal from the glass 
support and for which it was still possible to obtain a consolidated film by compression molding. Films of $\mathrm{P}(\mathrm{VDF}-\mathrm{TrFE})$ were also prepared as references following the same procedures. In what follows solvent cast materials are indicated with the code SC- $x x-y$, solvent cast annealed materials with the code SCA- $x x-y$, and compression molded materials with the code CM- $x x-y$, where $x x$ indicates the percent in volume of $\mathrm{BaTiO}_{3}$ and $y$ is equal to 1 or 2 for materials containing BT-1 or BT-2 particles, respectively.

\section{Methods}

The particle size of the $\mathrm{BaTiO}_{3}$ powders was measured with a Mastersizer particle size analyzer (Malvern Instruments Ltd., UK), after disagglomerating the particles with an ultrasound horn for $15 \mathrm{~min}$ in a solution of polyacrylic acid (PAA) at $0.01 \mathrm{wt} \%$ in water and $\mathrm{NH}_{3}$, with an $\mathrm{NH}_{3} /$ PAA molar ratio of 1.5. X-ray diffraction was performed on the $\mathrm{BaTiO}_{3}$ powders and on the films using $\mathrm{CuK} \alpha$ radiation on a D8 Discover diffractometer (Bruker AXS, USA). The morphology of the nanocomposites was observed in a Philips XL30 FEG (Philips, The Netherlands) scanning electron microscope (SEM). The samples were prepared by cryo-fracture and carbon coated to prevent charging.

The thermal properties of the $\mathrm{BaTiO}_{3}$ powders and of the films were studied by means of differential scanning calorimetry (DSC Q100, TA Instruments, USA). The measurements were carried out between -80 and $200{ }^{\circ} \mathrm{C}$ at a heating/cooling rate of $10 \mathrm{~K} / \mathrm{min}$ under $\mathrm{N}_{2}$ flow. Thermogravimetric analysis (Mettler Toledo TGA/SDTA 851) was performed between 30 and $800{ }^{\circ} \mathrm{C}$ at $10 \mathrm{~K} / \mathrm{min}$ under $\mathrm{N}_{2}$ flow in alumina crucibles. Dynamic mechanical analysis (Q800 DMA, TA Instruments, USA) was performed on the films in tensile configuration between -50 and $150{ }^{\circ} \mathrm{C}$ at a heating rate of $3 \mathrm{~K} / \mathrm{min}$. The excitation frequency was $1 \mathrm{~Hz}$ and the applied strain was $0.05 \%$ in order to stay within the linear viscoelastic region, which was smaller for the composites than for the pure polymer.

Gold electrodes were deposited on the films by sputtering. Capacitance and losses were measured as a function of frequency with an impedance/gain-phase analyzer HP4194A at room temperature between $100 \mathrm{~Hz}$ and $1 \mathrm{MHz}$ and with AC voltage of $1 \mathrm{~V}_{\mathrm{rms}}$. Relative permittivity was then calculated from capacitance. Poling of the samples was performed in silicone oil. The desired electric field was applied for $30 \mathrm{~min}$ at $110^{\circ} \mathrm{C}$ and then for further 30 min while cooling to $35^{\circ} \mathrm{C}$. The piezoelectric coefficient $d_{33}$ was measured with a Berlincourt-type $d_{33}$-meter. The first measurement was taken $1 \mathrm{~h}$ after poling and then further measurements were performed in the following days in order to assess aging.

\section{Results and discussion}

Powder characterization

BT-1 powder was found to have a mean particle size of $1 \mu \mathrm{m}$ and BT- 2 of $0.7 \mu \mathrm{m}$. The XRD patterns of BT- 1 and BT-2 reproduced in Fig. 1 revealed higher tetragonality for the BT-2 powder as indicated by the better separation of the (200) and (002) peaks, visible between $2 \theta=44^{\circ}$ and $2 \theta=46.5^{\circ}$. The DSC measurements (Fig. 2) showed for both powders a peak at $129^{\circ} \mathrm{C}$ upon heating (inset in the figure) and a peak at $120^{\circ} \mathrm{C}$ upon cooling, that can be attributed to the transition from the tetragonal piezoelectric phase to the cubic paraelectric phase and vice versa (Curie temperature, $T_{\mathrm{c}}$ ) of $\mathrm{BaTiO}_{3}$. The $\Delta H$ of the transition was greater for BT-2 $(\Delta H=0.4 \mathrm{~J} / \mathrm{g})$ than for BT-1 $(\Delta H=0.2 \mathrm{~J} / \mathrm{g})$, indicating higher amount of tetragonal phase in the BT-2 powder [48, 49].

Structure and morphology of the films

The XRD patterns of the pure $\mathrm{P}(\mathrm{VDF}-\mathrm{TrFE})$ and composite films are shown in Fig. 1. The SC-0 film showed a peak at $2 \theta=20^{\circ}$ corresponding to the piezoelectric all trans crystalline phase of $\mathrm{P}(\mathrm{VDF}-\mathrm{TrFE})$ and a weak shoulder at lower $2 \theta$ attributed to the amorphous phase [50, 51]. The shoulder of the amorphous phase disappeared for the SCA- 0 and CM-0 films, and the peak at $2 \theta=20^{\circ}$ became

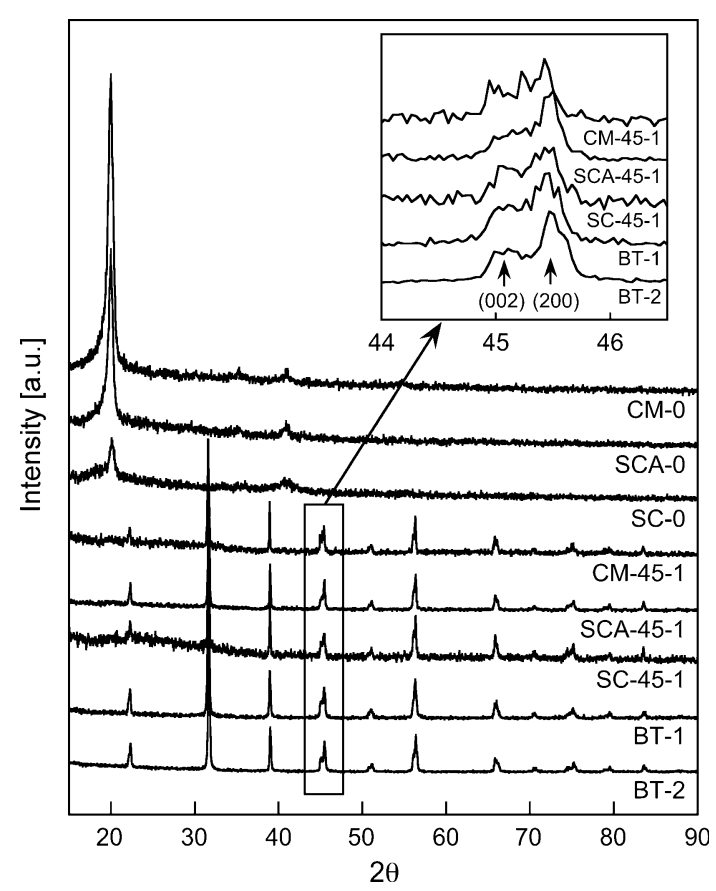

Fig. 1 XRD patterns of BT-1 and BT-2 powders, P(VDF-TrFE) and composite films. In the inset is shown the $\mathrm{BaTiO}_{3}$ double peak corresponding to the reflections of (200) and (002) planes 


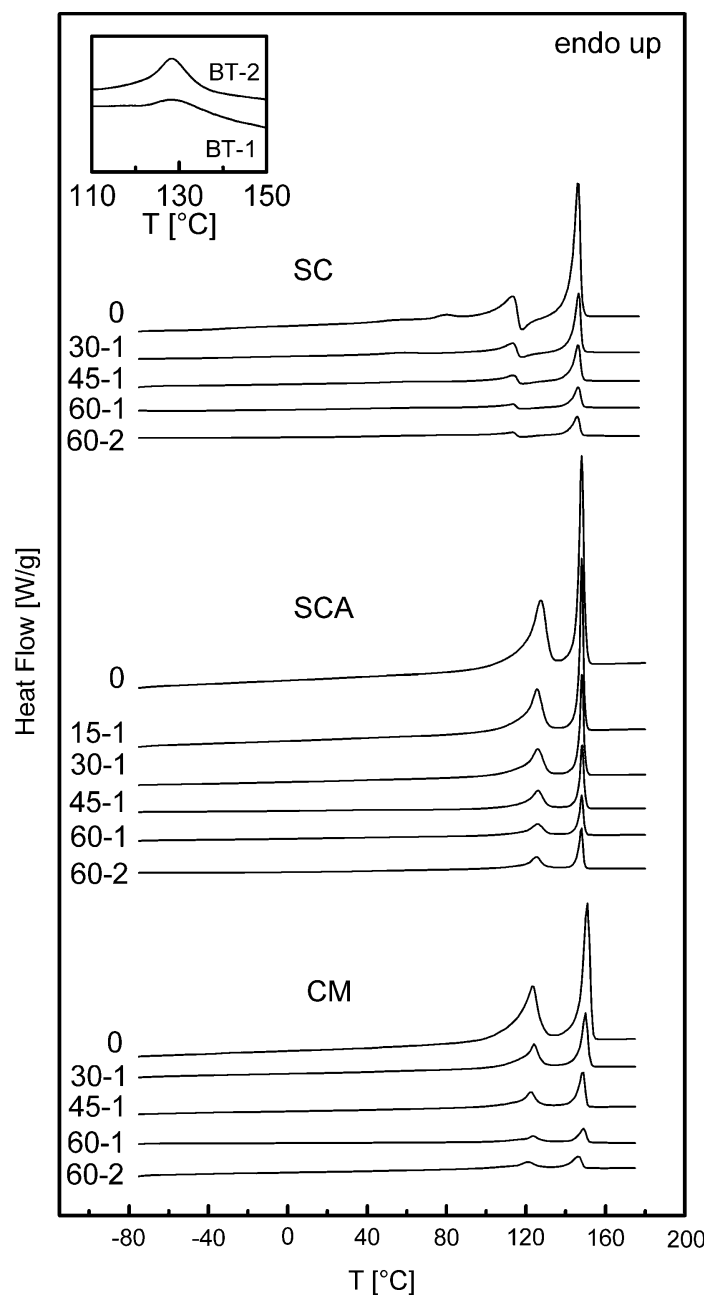

Fig. 2 DSC heating thermograms of SC, SCA, and CM films, and of BT-1 and BT-2 powders (inset). For legibility the scale of the heat flow of the BT powders is 50:1 with respect to that of the films

narrower and more intense. This indicates that the SCA-0 and $\mathrm{CM}-0$ films have a better-developed crystalline piezoelectric phase than the SC-0 films. For all the composite films, the double peak corresponding to the reflections of the (200) and (002) planes of $\mathrm{BaTiO}_{3}$ was equal to that of the pure BT-1 powder, indicating no change in the $\mathrm{BaTiO}_{3}$ structure during processing, as expected since the tetragonal phase is stable at room temperature.

SEM micrographs of cryo-fractured surfaces of the SC and CM films are shown in Figs. 3 and 4, respectively. The solvent cast films prepared with BT-1 showed a relatively good through thickness distribution of the $\mathrm{BaTiO}_{3}$ particles; however, powder agglomerates and polymer rich areas were visible. The films prepared with BT-2 showed a better dispersion of the $\mathrm{BaTiO}_{3}$ particles, with no polymer rich areas and fewer and smaller aggregates. The compression molding step helped to eliminate the polymer rich areas in the films, therefore obtaining more homogeneous materials. On the other hand, in the samples with higher amounts of ceramics the interface between the superposed layers was still visible in some areas, as highlighted, e.g., in Fig. $4 a$, c.

\section{Thermal properties}

Thermogravimetric analysis was performed on SC and CM materials. The results highlighted that the presence of $\mathrm{BaTiO}_{3}$ increased the thermal stability of both $\mathrm{SC}$ and $\mathrm{CM}$ materials. The decomposition temperatures are reported in Table 1.

DSC thermograms of SC, SCA, and CM materials are shown in Fig. 2. The heating thermograms of the SC films showed an endotherm peak corresponding to the Curie transition, partially overlapping with an exotherm peak attributed to recrystallization of the polymer. This behavior is documented for $\mathrm{P}(\mathrm{VDF}-\mathrm{TrFE})$ copolymers crystallized at low temperatures [52]. The endotherm peak at $146.3 \pm$ $0.2{ }^{\circ} \mathrm{C}$ was attributed to melting of the crystalline phase of the polymer. It is clear that the $\Delta H_{\mathrm{f}}$ measured for these films is related to their crystallinity after recrystallization. Therefore, it is not representative of the amount of crystalline phase present in the as made films. The heat capacity step $\left(\Delta C_{p}\right)$ corresponding to the glass transition of the amorphous phase of $\mathrm{P}(\mathrm{VDF}-\mathrm{TrFE})$ was detected at a temperature $T_{\mathrm{g}}=-32{ }^{\circ} \mathrm{C}$ for SC- 0 , however, $T_{\mathrm{g}}$ could not be detected for the composites due to the lower amount of polymer present in the materials. The heating thermograms of the SCA films showed two endotherm peaks corresponding to the Curie transition at $T_{\mathrm{c}}=126.1 \pm 0.7{ }^{\circ} \mathrm{C}$ and to melting at $148.1 \pm 0.1{ }^{\circ} \mathrm{C}$, respectively. The melting peak was sharper and the $\Delta H_{\mathrm{f}}$ slightly higher with respect to what observed for the SC films. This indicates that the annealing step not only allowed the recystallization, to an even slightly higher extent than observed during the DSC heating cycle of the SC films, but also that the crystallites obtained were more perfect and with a narrower size distribution. The heating thermograms of the CM films showed two endotherm peaks corresponding to the Curie transition at $T_{\mathrm{c}}=123.1 \pm 1.8{ }^{\circ} \mathrm{C}$ and to melting at $148.5 \pm 1.7^{\circ} \mathrm{C}$. The melting peak, though, was broader and the $\Delta H_{\mathrm{f}}$ was lower than for the SCA materials, indicating that the compression molding step resulted in a broader size distribution of the crystallites and lower crystallinity of the polymer.

To assess the effect of the addition of $\mathrm{BaTiO}_{3}$ particles on the crystallinity of the polymer phase, the $\Delta H_{\mathrm{f}}$ measured for the composites may be compared to the $\Delta H_{\mathrm{f}}$ measured for the pure polymer. Theoretically the $\Delta H_{\mathrm{f}}$ measured for the composites should scale proportionally to the P(VDFTrFE) mass fraction, if the presence of $\mathrm{BaTiO}_{3}$ does not affect the degree of crystallinity. The theoretical $\Delta H_{\mathrm{f}}$ for the composites is calculated as: 

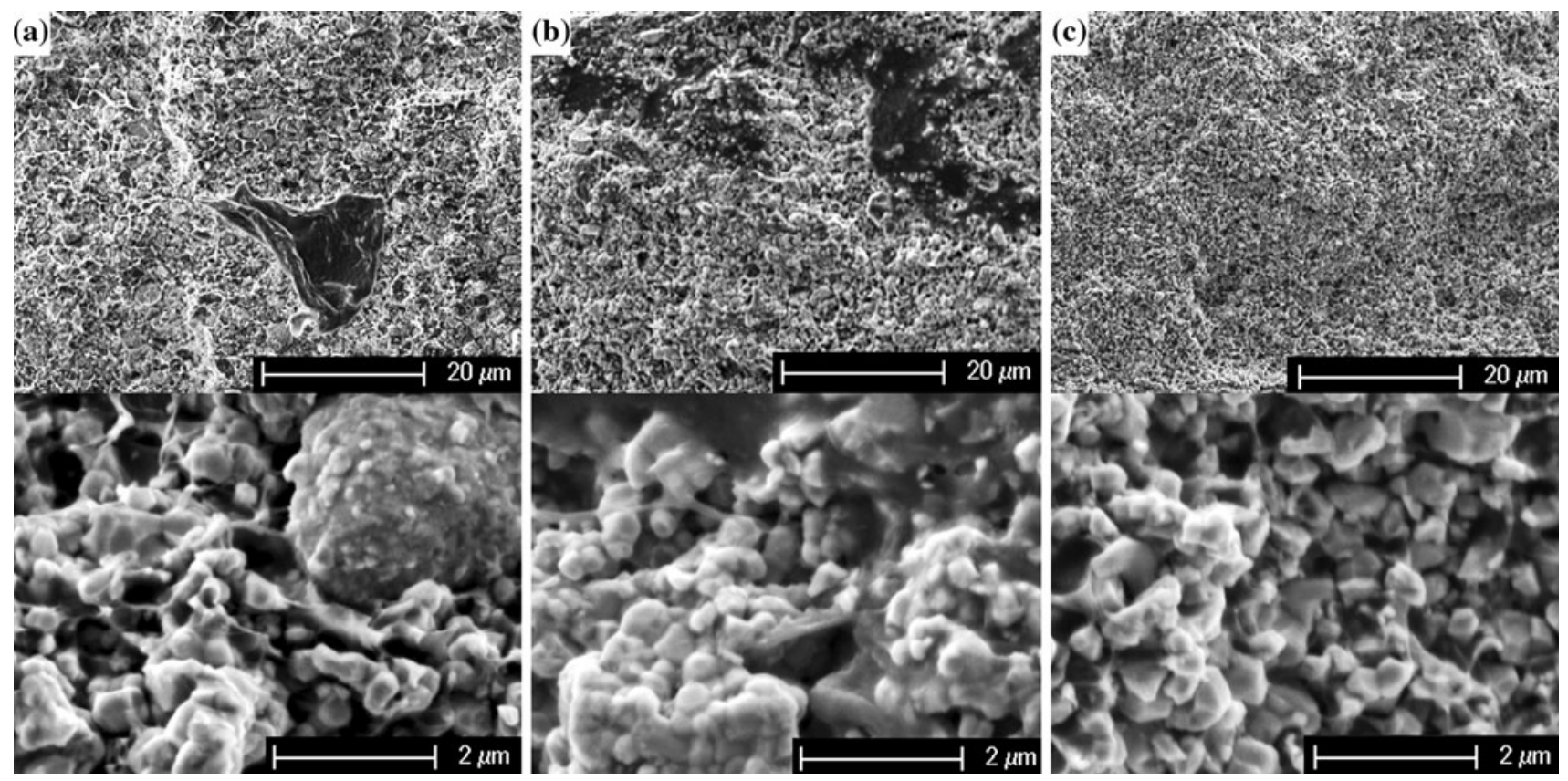

Fig. 3 SEM micrographs of a SC-30-1, b SC-60-1, and c SC-60-2
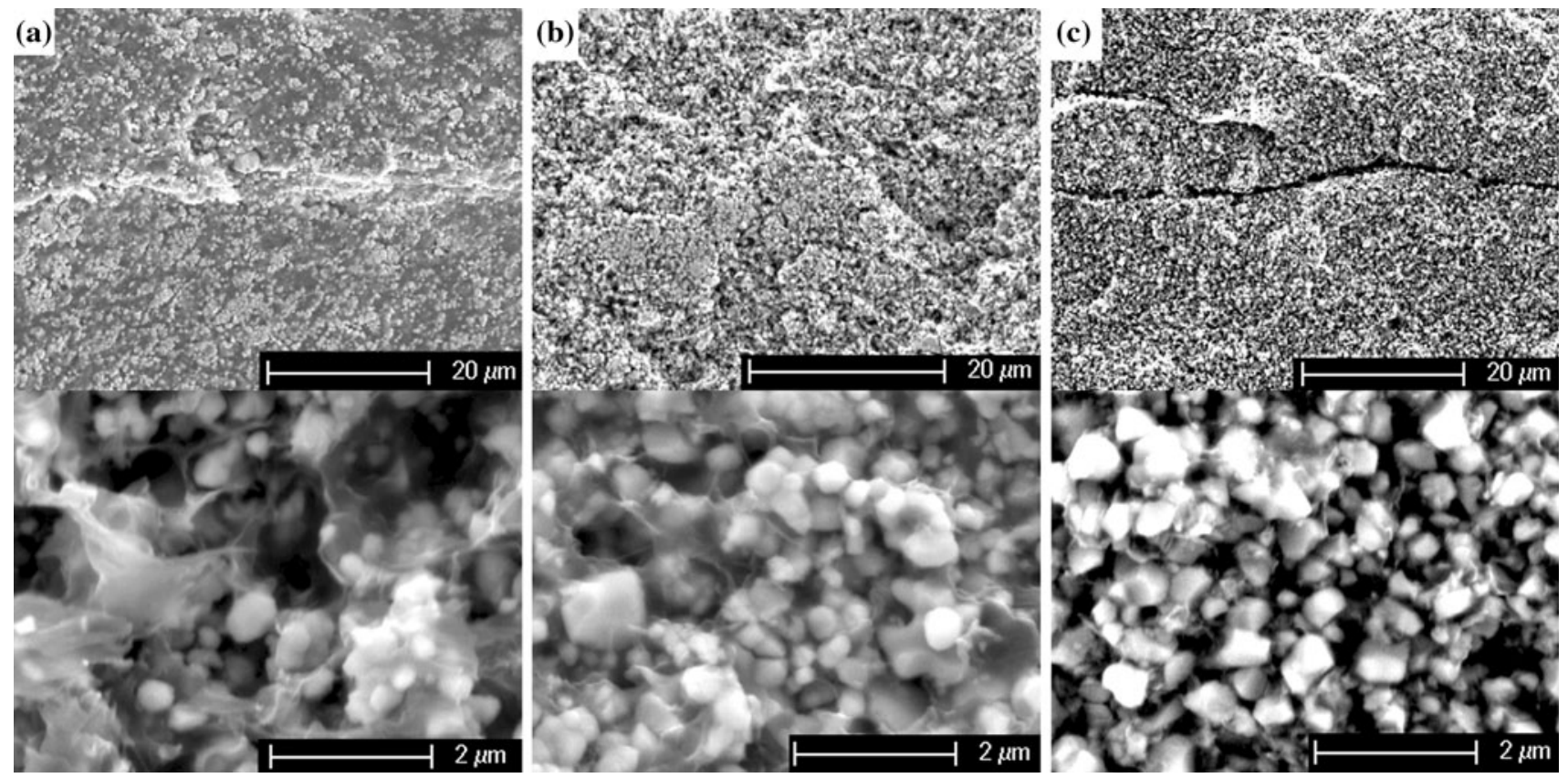

Fig. 4 SEM micrographs of a CM-30-1, b CM-60-1, and c CM-60-2

$$
\Delta H_{\mathrm{f}}=\Delta H_{\mathrm{f}}^{\mathrm{m}} \cdot w_{\mathrm{p}}=\Delta H_{\mathrm{f}}^{\mathrm{m}} \cdot \frac{\rho_{\mathrm{P}} \phi_{\mathrm{P}}}{\rho_{\mathrm{P}} \phi_{\mathrm{P}}+\rho_{\mathrm{B}} \phi_{\mathrm{B}}}
$$

where $w_{\mathrm{P}}$ indicates the mass fraction of $\mathrm{P}(\mathrm{VDF}-\mathrm{TrFE})$ in the composites, $\phi_{\mathrm{P}}$ and $\phi_{\mathrm{B}}$ the volume fractions of $\mathrm{P}(\mathrm{VDF}-$ TrFE) and $\mathrm{BaTiO}_{3}$, respectively, and $\rho_{\mathrm{P}}$ and $\rho_{\mathrm{B}}$ their respective densities. The density of $\mathrm{P}(\mathrm{VDF}-\mathrm{TrFE})$ has been taken equal to $1.9 \mathrm{~g} / \mathrm{cm}^{3}$ [53] and that of $\mathrm{BaTiO}_{3}$ equal to
$6.08 \mathrm{~g} / \mathrm{cm}^{3}$ according to the supplier's information. The comparison between the theoretical and experimental values is shown in Fig. 5. The $\Delta H_{\mathrm{f}}$ of the SC and SCA materials decreased proportionally to the weight fraction of the polymer in the composites, indicating that the presence of the BT did not modify the degree of crystallinity of the $\mathrm{P}(\mathrm{VDF}-\mathrm{TrFE})$ matrix. Again, it must be remembered that the $\Delta H_{\mathrm{f}}$ values reported for the $\mathrm{SC}$ films were measured 
Table 1 Decomposition temperatures $T_{\mathrm{d}}$ of SC and CM P(VDFTrFE) and composites

\begin{tabular}{lcccc}
\hline $\mathrm{BaTiO}_{3}$ & & & $T_{\mathrm{d}}\left({ }^{\circ} \mathrm{C}\right)$ & \\
\cline { 5 - 5 } Powder & vol\% & & SC & CM \\
\hline BT-1 & 0 & 482 & 483 \\
& 30 & 495 & 496 \\
& 60 & 492 & 496 \\
BT-2 & 60 & 489 & 490 \\
\hline
\end{tabular}

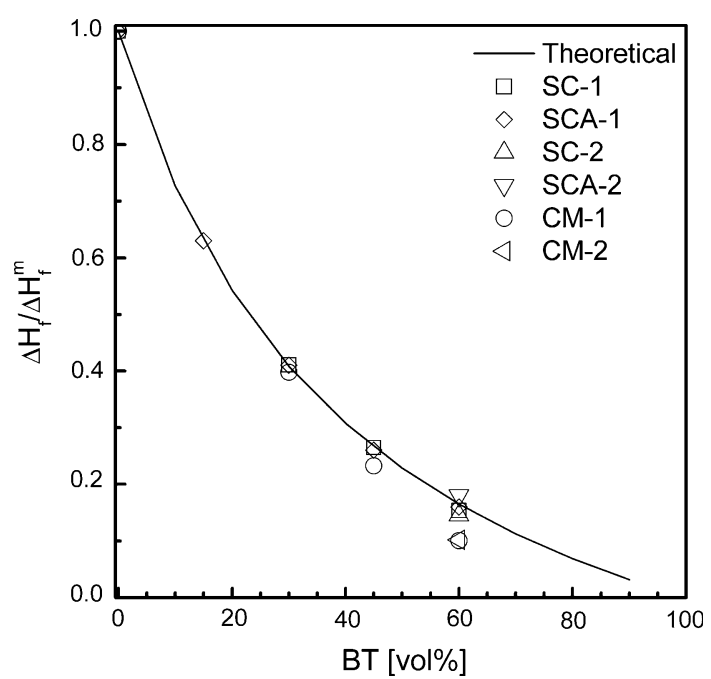

Fig. 5 Theoretical and experimental values of the ratio between the heat of fusion of the composites $\left(\Delta H_{\mathrm{f}}\right)$ and that of the pure polymer $\left(\Delta H_{\mathrm{f}}^{\mathrm{m}}\right)$

after recrystallization. For the CM materials the decrease was slightly higher than the theoretical one, suggesting that in this case the addition of $\mathrm{BaTiO}_{3}$ particles led to decreased crystallinity of the polymer matrix.

\section{Dynamic mechanical analysis}

The storage modulus $E^{\prime}$ and ratio of the loss modulus $E^{\prime \prime}$ to the storage modulus $E^{\prime}(\tan \delta)$ of $\mathrm{P}(\mathrm{VDF}-\mathrm{TrFE})$ and composite SC films are shown in Fig. 6a, b. The modulus of SC-0 showed a marked decrease with temperature until about $100{ }^{\circ} \mathrm{C}$. Then it started to increase slightly, before leveling off and finally decreasing again approaching the melting temperature. The modulus increase around $100{ }^{\circ} \mathrm{C}$ corresponds to the appearance of the exotherm peak in the DSC measurements and supports the hypothesis of a recrystallization. The modulus of SC-30-1 was higher than that of SC- 0 , and followed the same trends. The composites containing more than $30 \mathrm{vol} \%$ of $\mathrm{BaTiO}_{3}$ failed between 100 and $105{ }^{\circ} \mathrm{C}$ under the small strain applied. It must be remarked here that if no strain is applied the materials do not fail at these temperatures for the only effect of thermal stress, which allows poling at high temperatures. SC-45-1 and SC-60-1 showed a lower $E^{\prime}$ than SC-30-1 at low temperatures.

The reduction in modulus with increasing filler content may be attributed to the increased inhomogeneity and porosity of the materials with high ceramics volume fraction. However, their moduli decreased less steeply with temperature so that above $40-50{ }^{\circ} \mathrm{C}$ the curves of SC-45-1 and SC-60-1 lied above that of SC-30-1. This may be attributed to the fact that above $40{ }^{\circ} \mathrm{C}$ the polymer has a very low modulus; therefore the reinforcing effect of the filler has a much higher impact on the final modulus of the composite than at low temperature. SC-60-2 showed the highest modulus among the SC materials. This can be explained in the light of the better dispersion of the BT-2 particles, with smaller aggregates, as shown by the SEM images. The $\tan \delta$ curves of all the SC materials showed a peak at $-33 \pm 2{ }^{\circ} \mathrm{C}$, corresponding to the segmental motions in the amorphous phase ( $\beta$-relaxation). A second relaxation process, named $\alpha$-relaxation, the nature of which is still debated, appeared above $40{ }^{\circ} \mathrm{C}$ [54-56]. For the pure $\mathrm{P}(\mathrm{VDF}-\mathrm{TrFE})$ and for the composite filled with BT-2 the $\alpha$-relaxation process started at lower temperature than for the composites filled with BT-1. The reason for this difference in temperature is not clearly understood. The $\tan \delta$ of the materials increased with $\mathrm{BaTiO}_{3}$ volume fraction, with the higher $\tan \delta$ corresponding to SC-60-2. The only exception was SC-30-1, which had the lowest $\tan \delta$ at temperatures below $50{ }^{\circ} \mathrm{C}$. This is opposite to what is expected upon addition of rigid filler in a polymer matrix and may be attributed to increased porosity in the specimens with higher amounts of $\mathrm{BaTiO}_{3}$ particles.

The storage moduli $E^{\prime}$ and $\tan \delta$ of SCA films are reported in Fig. $6 \mathrm{c}$, d. The storage modulus of the SCA-0 film showed a less marked decrease with temperature than that of the SC-0 film. A first small drop of $E^{\prime}$ was seen at about $-30{ }^{\circ} \mathrm{C}$, corresponding to the $\beta$-relaxation. A steeper decrease in $E^{\prime}$ occurred after $110^{\circ} \mathrm{C}$, attributable to the Curie transition of the $\mathrm{P}(\mathrm{VDF}-\mathrm{TrFE})$. Then above $135{ }^{\circ} \mathrm{C}$ a further drop in modulus was associated with the melting of the polymer. The storage moduli of the SCA composites containing BT-1 particles increased with $\mathrm{BaTiO}_{3}$ concentration up to $30 \mathrm{vol} \%$, and then decreased upon further BT-1 addition, similarly to what observed for SC films. The $E^{\prime}$ curves of SCA-15-1 and SCA-30-1 showed similar behavior to that of SCA-0. The $E^{\prime}$ of SCA-45-1 and SCA60-1 on the other hand started at lower values but decreased at a smaller rate with temperature, as already observed for the SC films. The decrease in modulus above 30 vol\% $\mathrm{BaTiO}_{3}$ may again be explained by the poorer dispersion of the filler at high concentrations or higher porosity. Around $120{ }^{\circ} \mathrm{C}$ the $E^{\prime}$ curve of SCA-45-1 crossed the $E^{\prime}$ curve of SCA-30-1, in correspondence with the drop 
Fig. 6 Storage modulus and $\tan \delta$ of a, b SC films, c, d SCA films, and e, f CM films

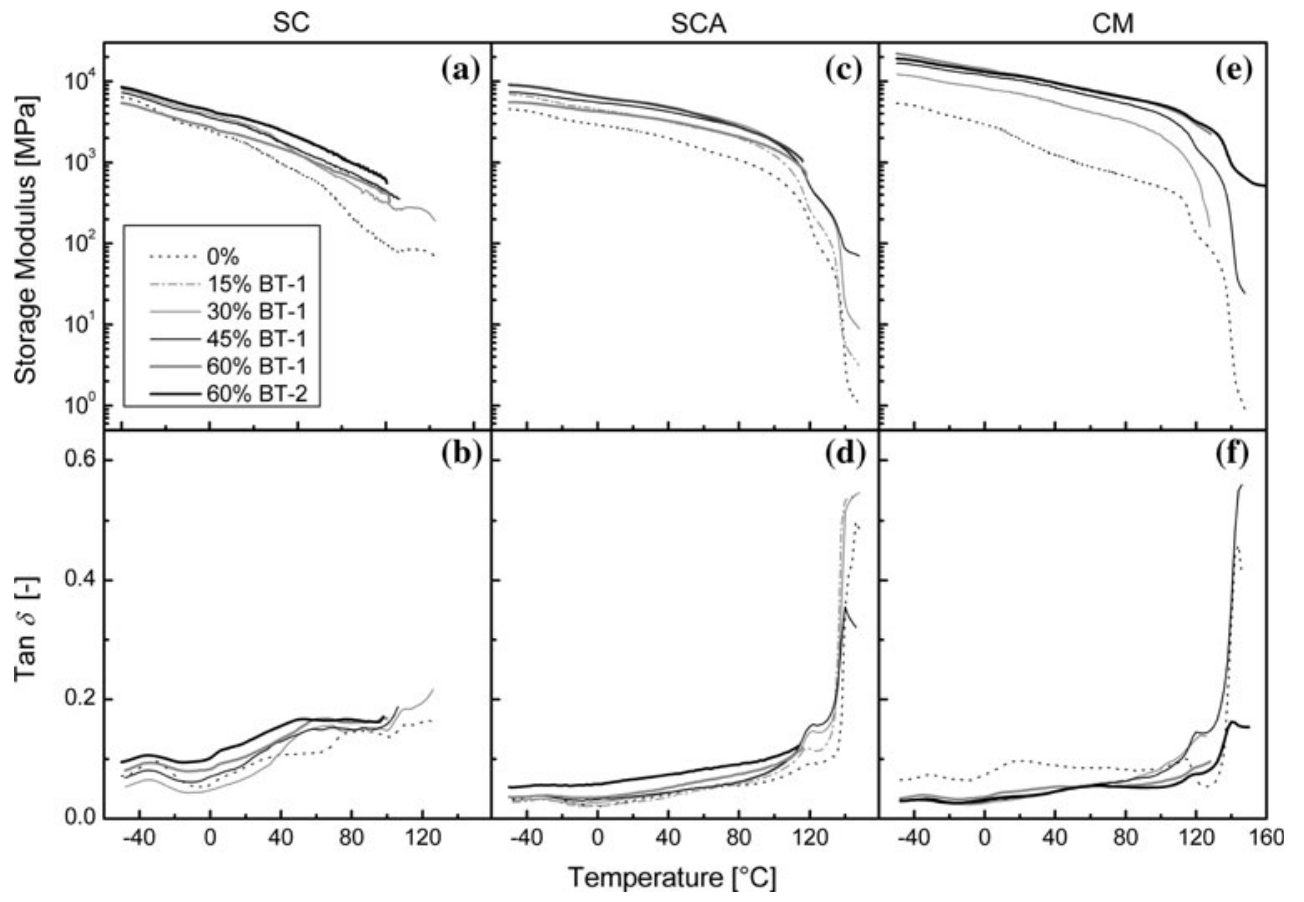

in modulus associated with the Curie transition. SCA-60-1 failed at $115{ }^{\circ} \mathrm{C}$, temperature at which its modulus had become comparable to that of SCA-30-1. SCA-60-2 showed a modulus about $50 \%$ higher than that of SCA-60-1 and comparable with that of SCA-30-1 up to $115^{\circ} \mathrm{C}$, temperature at which SCA-60-2 failed under the applied strain. As for the SC composites the higher modulus of SCA-60-2 compared to the composites filled with BT-1 is attributed to the better dispersion of BT-2 in the polymer matrix. The $\tan \delta$ curves of all SCA materials showed the peak at $-30{ }^{\circ} \mathrm{C}$, associated with the $\beta$-relaxation, although with reduced intensity compared with the SC materials, in agreement with the DSC results showing higher crystallinity of the P(VDF-TrFE) in the annealed materials. The $\alpha$-relaxation phenomenon weakly appeared for SCA-0 and was not visible for the SCA composites. A peak was visible at $120{ }^{\circ} \mathrm{C}$ corresponding to the Curie transition of both $\mathrm{P}(\mathrm{VDF}-\mathrm{TrFE})$ and $\mathrm{BaTiO}_{3}$, before the sharp increase in $\tan \delta$ at $140{ }^{\circ} \mathrm{C}$ corresponding to melting of the polymer. Tan $\delta$ increased upon addition of $\mathrm{BaTiO}_{3}$, except for SCA15-1, which had the lowest $\tan \delta$ at temperatures below $70{ }^{\circ} \mathrm{C}$. The higher $\tan \delta$ was shown by SCA-60-2, similarly to what was observed for SC films.

The storage modulus $E^{\prime}$ and $\tan \delta$ of the CM materials as a function of temperature are shown in Fig. 6e, f. The $E^{\prime}$ of the CM-0 film was found to have at low temperatures a similar value to that of the SCA-0 films. Three drops in modulus were present before the final drop due to melting. The first drop was attributed to the $\beta$-relaxation and the drop at $115^{\circ} \mathrm{C}$ to the Curie transition. The decrease in modulus starting at $5{ }^{\circ} \mathrm{C}$ may be attributed to the $\alpha$-relaxation, which was more pronounced than for the SCA materials. The modulus of the composite materials increased with increasing $\mathrm{BaTiO}_{3}$ concentration, but below $135{ }^{\circ} \mathrm{C}$ this increase leveled off beyond 45 vol\% $\mathrm{BaTiO}_{3}$. At all $\mathrm{BaTiO}_{3}$ concentrations the storage modulus $E^{\prime}$ steadily decreased with temperature between -50 and $110^{\circ} \mathrm{C}$, the drops in $E^{\prime}$ associated with the $\beta$ and $\alpha$ relaxations being smaller than for the pure polymer. Then at about $110{ }^{\circ} \mathrm{C}$ the drop in modulus associated with the Curie transition appeared, the magnitude of which decreased with increasing BT concentration, followed by a less steep decrease up to about $135^{\circ} \mathrm{C}$. Then another drop in $E^{\prime}$ happened due to melting of the polymer matrix, once again of smaller magnitude for the composites containing higher volume of $\mathrm{BaTiO}_{3}$. The value of $\tan \delta$ was lower for the composites than for the pure polymer as it would be expected upon addition of a rigid phase. This different behavior than for the SC and SCA materials may be attributed to the reduced inhomogeneities and porosity following the compression molding step. A $\tan \delta$ peak was present for $\mathrm{CM}-0$ at $-30{ }^{\circ} \mathrm{C}$, and for the composites between -32 and $-35{ }^{\circ} \mathrm{C}$, attributed to the $\beta$-relaxation. The $\alpha$-relaxation peak was visible at about $18{ }^{\circ} \mathrm{C}$ for $\mathrm{CM}-0$, but was not detected for the composites. The peak attributed to the Curie transition was present for all materials between 115 and $120{ }^{\circ} \mathrm{C}$, before the sharp increase due to melting of the polymer at $140{ }^{\circ} \mathrm{C}$.

Lower and upper bounds for the modulus of a two-phase material may be calculated from the volume fractions and moduli of each phase using the Hashin and Shtrikman model [57]. According to this model the lower bounds for 
the bulk $\left(K^{\mathrm{L}}\right)$ and shear $\left(G^{\mathrm{L}}\right)$ moduli of a two-phase material are given by:

$$
\begin{aligned}
K^{\mathrm{L}} & =K_{\mathrm{P}}+\frac{1}{\frac{1}{\left(K_{\mathrm{c}}-K_{\mathrm{p}}\right)}+\frac{3 v_{\mathrm{c}}}{\left(3 K_{\mathrm{P}}+4 G_{\mathrm{P}}\right)}} \\
G^{\mathrm{L}} & =G_{\mathrm{P}}+\frac{v_{\mathrm{c}}}{\frac{1}{G_{\mathrm{p}}-G_{\mathrm{c}}}+\frac{6\left(K_{\mathrm{p}}+2 G_{\mathrm{p}}\right) v_{\mathrm{p}}}{5 G_{\mathrm{p}}\left(3 K_{\mathrm{p}}+G_{\mathrm{p}}\right)}}
\end{aligned}
$$

where $K, G$, and $v$ indicate the bulk modulus, shear modulus and Poisson's coefficient, and the subscripts $\mathrm{p}$ and c indicate in our case the polymer and ceramic phase, respectively. The upper bounds $K^{\mathrm{U}}$ and $G^{\mathrm{U}}$ are obtained by exchanging the subscripts $\mathrm{p}$ and $\mathrm{c}$ in the equations above. The lower $\left(E^{\mathrm{L}}\right)$ and upper $\left(E^{\mathrm{U}}\right)$ bounds for the Young's modulus may be then be calculated from:

$$
\begin{aligned}
& E^{\mathrm{L}}=\frac{9 K^{\mathrm{L}} G^{\mathrm{L}}}{3 K^{\mathrm{L}}+G^{\mathrm{L}}} \\
& E^{U}=\frac{9 K^{U} G^{U}}{3 K^{U}+G^{U}}
\end{aligned}
$$

The Hashin and Shtrikman bounds were calculated for the modulus of the SC, SCA, and $\mathrm{CM}$ materials at $25^{\circ} \mathrm{C}$ and compared to the experimental values in Fig. 7. The Young's moduli of the matrices were taken to be equal to their $E^{\prime}$ measured by DMA in this study, and the Poisson's ratio was taken equal to 0.3 . For the $\mathrm{BaTiO}_{3}$ the Young's modulus was taken equal to $120 \mathrm{GPa}$ and the Poisson's ratio equal to 0.35 [58]. The corresponding values of $K$ and $G$ to be introduced in the Eqs. 2 and 3 were calculated from:

$$
\begin{gathered}
K_{\mathrm{c}}=\frac{E_{\mathrm{c}}}{3\left(1-2 v_{c}\right)} ; K_{\mathrm{p}}=\frac{E_{\mathrm{p}}}{3\left(1-2 v_{\mathrm{p}}\right)} \\
G_{\mathrm{c}}=\frac{E_{\mathrm{c}}}{2\left(1-v_{\mathrm{c}}\right)} ; G_{\mathrm{p}}=\frac{E_{\mathrm{p}}}{2\left(1-v_{\mathrm{p}}\right)}
\end{gathered}
$$

For the SC and SCA composites the experimental values of the modulus were coincident with the lower bound up to 30 vol\% $\mathrm{BaTiO}_{3}$, and below the lower bound for higher filler fractions. Such behavior is again consistent with a

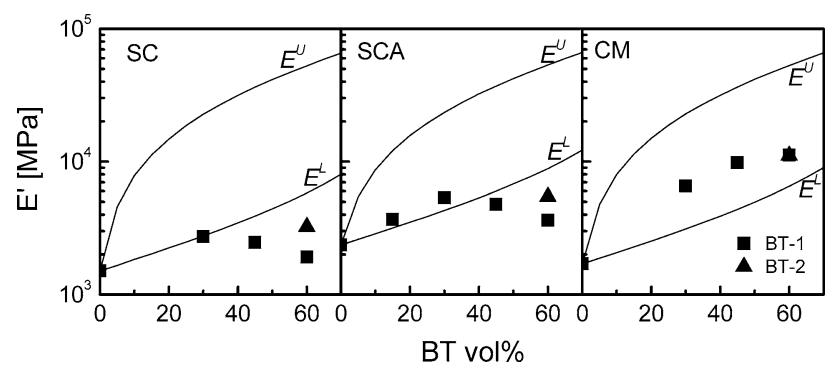

Fig. 7 Hashin and Shtrikman bounds and experimental values for the storage modulus of SC, SCA, and CM materials at $25{ }^{\circ} \mathrm{C}$ high porosity of these materials at high $\mathrm{BaTiO}_{3}$ volume fractions. For the CM composites the experimental values of the modulus were slightly higher than the lower bound in the whole range of compositions. A similar result was obtained, e.g., by Tessier-Doyen et al. [59] for a vitreous matrix containing spherical alumina particles.

Owing to the shape and morphology of the materials, an experimental determination of the porosity was not straightforward. Therefore, a rough estimate of the amount of porosity which would cause a decrease in modulus as seen for the SC materials containing more than $45 \%$ $\mathrm{BaTiO}_{3}$ has been attempted theoretically. For simplicity it was assumed that all the porosity was in the polymer matrix, and therefore the matrix was considered as a foam, with a modulus that was lower than that of the non porous polymer. Then for the SC-45-1 and SC-60-1 the Hashin and Strickman's model was used to calculate the moduli of the matrix needed to have a lower bound corresponding with the experimental values of the moduli. These calculated matrix moduli were then considered as the moduli of a closed pores foam, for which:

$\frac{E_{\mathrm{f}}}{E_{\mathrm{p}}}=0.32\left[\left(1-\phi_{\mathrm{v}}\right)^{2}+\left(1-\phi_{\mathrm{v}}\right)\right]$

where $\phi_{\mathrm{v}}$ is the volume fraction of pores in the foam. Knowing $\phi_{\mathrm{v}}$ it was possible to calculate the corresponding volume fraction of pores referred to the whole composite material, which for SC-45-1 and SC-60-1 resulted of 15 and $22 \%$, respectively.

Dielectric properties

The relative permittivity and losses as a function of frequency of films containing $60 \mathrm{vol} \%$ of BT-2 are shown in Fig. 8. In the whole range of frequency SC and SCA materials showed a lower permittivity than $\mathrm{CM}$ ones. This may be attributed to higher porosity in the SC composites. In fact if we take for the SC-60-1 composite the calculated porosity value of $22 \%$, and assuming that the value of permittivity measured for the CM-60-1 material (124) corresponded to $0 \%$ porosity, we can apply the logarithmic rule of mixtures to take porosity into account:

$\log \varepsilon=\phi_{\mathrm{s}} \log \varepsilon_{\mathrm{s}}+\phi_{\mathrm{v}} \log \varepsilon_{\mathrm{V}}$

where $\varepsilon, \varepsilon_{\mathrm{s}}$, and $\varepsilon_{\mathrm{v}}$ are the permittivities of the porous composite, of the non-porous composite, and of the voids and $\phi_{\mathrm{s}}$ and $\phi_{\mathrm{v}}$ are the volume fractions of the solid composite phase and of the pores, respectively. According to this calculation the permittivity of the non-porous SC-60-1 composite would be equal to 63 , which is close to the measured value for SC-60-2. As shown in Fig. 8 the relative permittivity increased with $\mathrm{BaTiO}_{3}$ content for the CM materials. At all $\mathrm{BaTiO}_{3}$ concentrations the permittivity 
was nearly constant between $10^{2}$ and $10^{4} \mathrm{~Hz}$ then it decreased. The losses were low (loss tangent $<0.05$ ) up to $10^{4} \mathrm{~Hz}$, then they rapidly increased at higher frequencies. This behavior is characteristic of the $\beta$-relaxation of P(VDF-TrFE) [56].

It must be noticed that the permittivity obtained with 60 vol\% BT-1 was higher than that obtained with 60 vol\% BT-2. This may be attributed to the dependence of the permittivity of $\mathrm{BaTiO}_{3}$ on grain size, the permittivity showing a maximum for $1 \mu \mathrm{m}$ grain size, and decreasing at smaller grain sizes.

A classical model for the relative permittivity as a function of the ceramic volume fraction is the Bruggeman's equation:

$1-\phi_{\mathrm{c}}=\frac{\varepsilon_{\mathrm{c}}-\varepsilon}{\varepsilon_{\mathrm{c}}-\varepsilon_{\mathrm{p}}}\left(\frac{\varepsilon_{\mathrm{p}}}{\varepsilon}\right)^{\frac{1}{3}}$

where $\phi_{\mathrm{c}}$ is the volume fraction of the ceramic and $\varepsilon_{\mathrm{c}}, \varepsilon_{\mathrm{p}}$, and $\varepsilon$ are the relative permittivities of the ceramic, the polymer, and the composites, respectively. Another model was proposed by Jayasundere and Smith [60], who modified the Kerner's equation [61] in order to take into account the interactions between neighboring dielectric particles: $\varepsilon=\frac{\varepsilon_{\mathrm{p}} \phi_{\mathrm{p}}+\varepsilon_{\mathrm{c}} \phi_{\mathrm{c}}\left[3 \varepsilon_{\mathrm{p}} /\left(\varepsilon_{\mathrm{c}}+2 \varepsilon_{\mathrm{p}}\right)\right]\left[1+\phi_{\mathrm{c}}\left(\varepsilon_{\mathrm{c}}-\varepsilon_{\mathrm{p}}\right) /\left(\varepsilon_{\mathrm{c}}+2 \varepsilon_{\mathrm{p}}\right)\right]}{\phi_{\mathrm{p}}+\phi_{\mathrm{c}}\left(3 \varepsilon_{\mathrm{p}}\right) /\left(\varepsilon_{\mathrm{c}}+2 \varepsilon_{\mathrm{p}}\right)\left[1+\phi_{\mathrm{c}}\left(\varepsilon_{\mathrm{c}}-\varepsilon_{\mathrm{p}}\right) /\left(\varepsilon_{\mathrm{c}}+2 \varepsilon_{\mathrm{p}}\right)\right]}$

The comparison of the experimental results for $\mathrm{CM}$ films at $10 \mathrm{kHz}$ with those calculated assuming the permittivity of $\mathrm{P}(\mathrm{VDF}-\mathrm{TrFE})$ equal to that measured for the pure polymer, and the permittivity of BT equal to 1,500 are shown in Fig. 9. The agreement between the experimental data and the Jayasundere model was excellent for the entire range of compositions, while the Bruggeman's model slightly underestimated the relative permittivity in the central part of the experimental range of compositions.

\section{Piezoelectric coefficient}

To choose an optimum polarization field, a series of poling experiments with increasing electrical field were conducted on CM-60-2. When the polarization field was increased from 25 to $100 \mathrm{kV} / \mathrm{cm}$, the $d_{33}$ increased initially with the applied field, and then started to level off, suggesting that full polarization was approached (see Fig. 10). However, it was not possible to verify by applying higher electric fields if full polarization was indeed reached, due to breakdown of the materials.
Fig. 8 Relative permittivity and loss tangent for a, c SC, $\mathrm{SCA}$, and $\mathrm{CM}$ composites containing 60 vol\% BT-2 and b, d CM P(VDF-TrFE) and composites filled with BT-1 particles

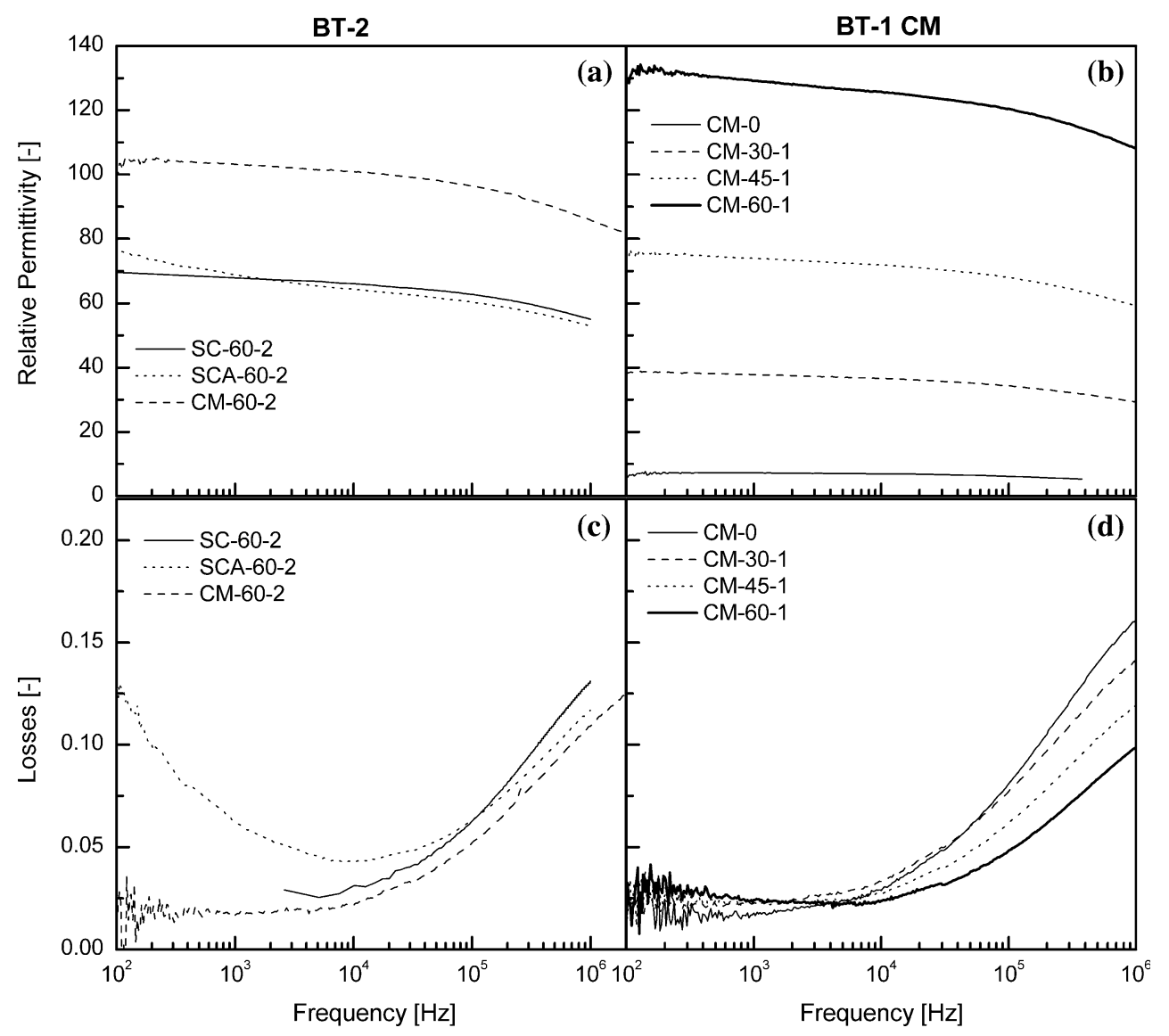




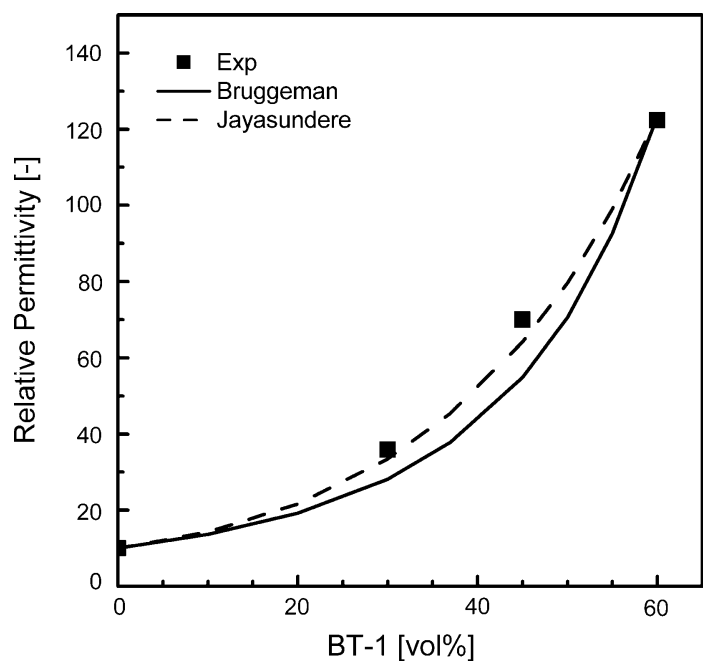

Fig. 9 Calculated and experimental values for the relative permittivity of $\mathrm{CM}$ materials at $10 \mathrm{kHz}$ as function of $\mathrm{BaTiO}_{3}$ content

As all the materials with lower amounts of $\mathrm{BaTiO}_{3}$ proved to be able to stand the applied field of $100 \mathrm{kV} / \mathrm{cm}$ without breakdown, this field was chosen for the study. The $d_{33}$ of the CM materials tested $1 \mathrm{~h}$ after poling increased linearly with $\mathrm{BaTiO}_{3}$ vol\% from $-5 \mathrm{pC} / \mathrm{N}$ for the pure polymer up to a value of $34 \mathrm{pC} / \mathrm{N}$ for $60 \mathrm{vol} \% \mathrm{BaTiO}_{3}$ (Fig. 10). The $d_{33}$ obtained for the pure polymer was low compared with the value achievable for this polymer, which is about $-30 \mathrm{pC} / \mathrm{N}$, however, it must be remembered that such high values are usually obtained with poling fields of the order of $500-1000 \mathrm{kV} / \mathrm{cm}$. The absolute value of the $d_{33}$ obtained for the films containing $60 \%$ $\mathrm{BaTiO}_{3}$ is comparable with the maximum value obtainable for the pure polymer (although in the opposite direction), but it was achieved applying a much lower poling field. The SC materials showed lower $d_{33}$ than the $\mathrm{CM}$ ones. This may be related to the lower permittivity.

\section{Aging}

When $d_{33}$ was measured as a function of time, a strong aging was observed for the composite materials, as highlighted in Fig. 11a. The aging rate depended on the type of powder, BT-2 showing less severe aging than BT-1, and on the $\mathrm{BT}$ vol\%, the aging rate increasing at lower BT concentrations. The aging was almost completely reversible, i.e., when an aged sample was poled again the $d_{33}$ obtained was up to $92 \%$ of the $d_{33}$ obtained with the first poling. A hypothesis on the cause of aging is stress release in the polymer. In fact during poling the domains of the ceramic phase are oriented in the direction of the field. This rotation creates a mechanical stress in the polymer. In time the polymer chains tend to release this stress and this may cause a partial loss of orientation of the domains ceramic
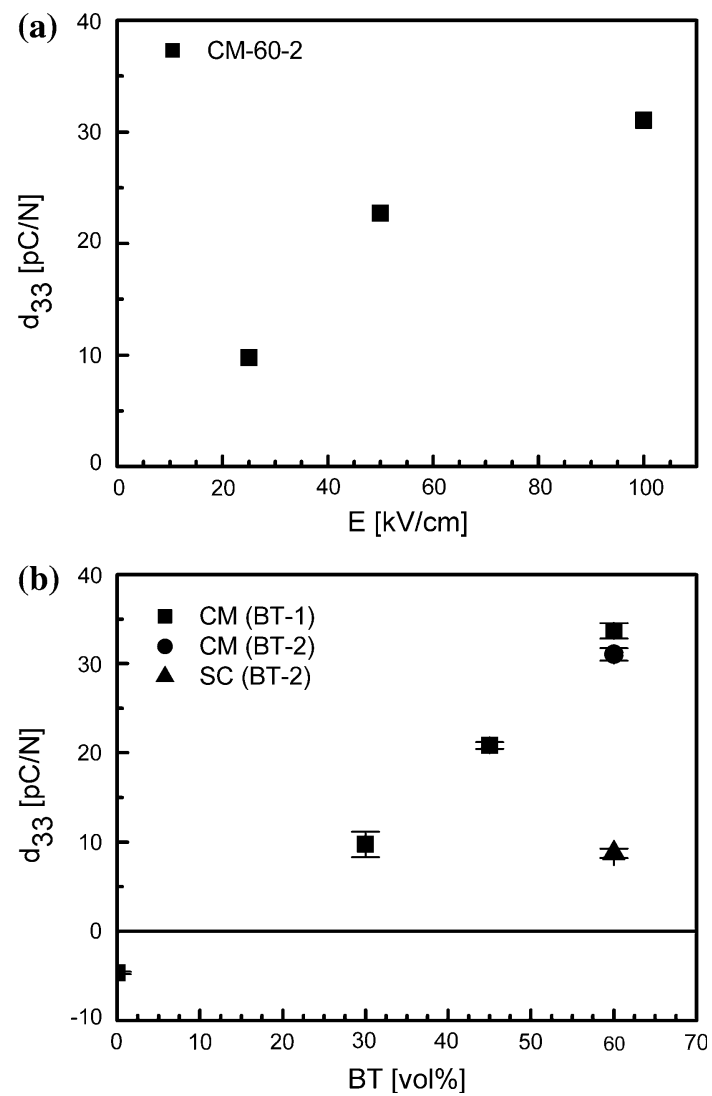

Fig. 10 Piezoelectric coefficient of a CM-60-2 as a function of poling field and b CM and SC materials poled at $100 \mathrm{kV} / \mathrm{cm}$ as a function of $\mathrm{BaTiO}_{3}$ content

phase. In order to support this hypothesis the permittivity of the samples was measured after poling and with aging time. The relative permittivity of the poled materials measured immediately after poling was lower than that of the corresponding unpoled materials, as expected, and the piezoelectric resonance peaks appeared in the permittivity patterns (Fig. 11b). Then an increase of the relative permittivity was observed for the poled samples with time after poling, which can be attributed to the loss of preferred orientations of some $\mathrm{BaTiO}_{3}$ domains and to the consequent increased density of domain walls. As a consequence the amplitude of the resonance peaks decreased.

\section{Summary}

According to the results of the structural and morphological characterization, the (0-3) $\mathrm{BaTiO}_{3} / \mathrm{P}(\mathrm{VDF}-\mathrm{TrFE})$ composites may be schematized as in Fig. 12. The amount of particle aggregates and porosity was found to be dependent on the volume percent and on the type of $\mathrm{BaTiO}_{3}$ powder, with porosity being also highly affected by the processing route. The crystalline structure of the polymeric matrix was mainly influenced by the processing route. 
Fig. 11 a Relative decrease of $d_{33}$ with aging time and b relative permittivity of $\mathrm{CM}$ 60-1 unpoled, poled, and aged for $2 \mathrm{~h}(2 \mathrm{~h})$ and 2 days $(2 \mathrm{~d})$ after poling
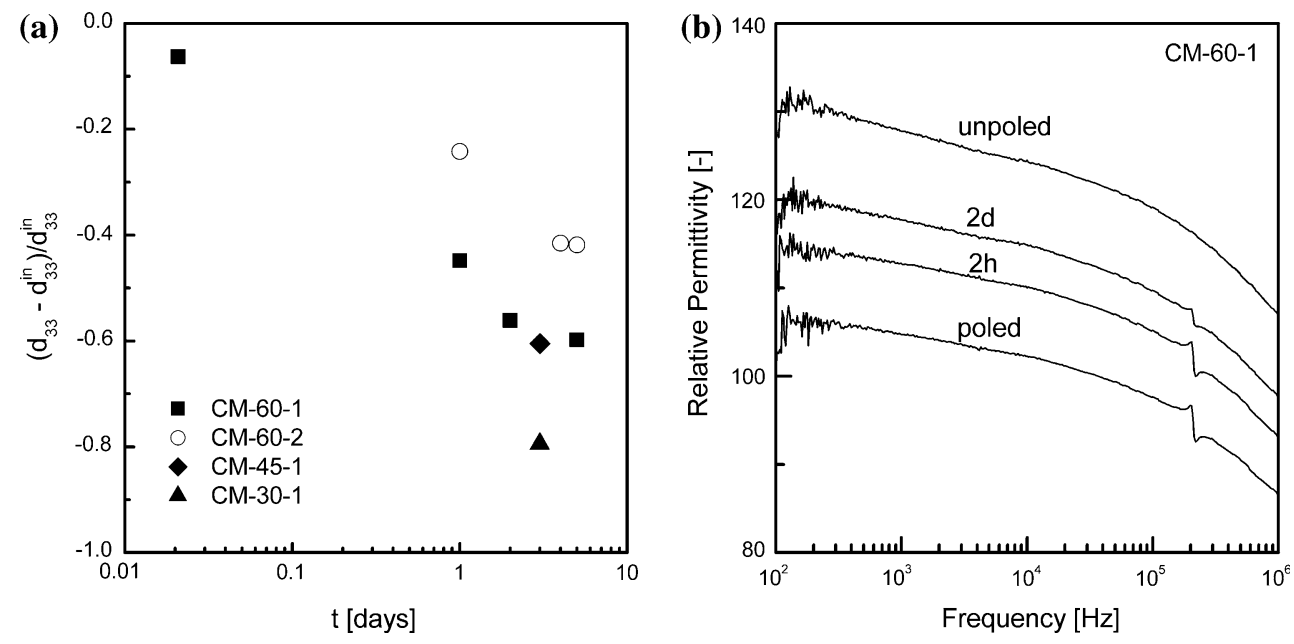

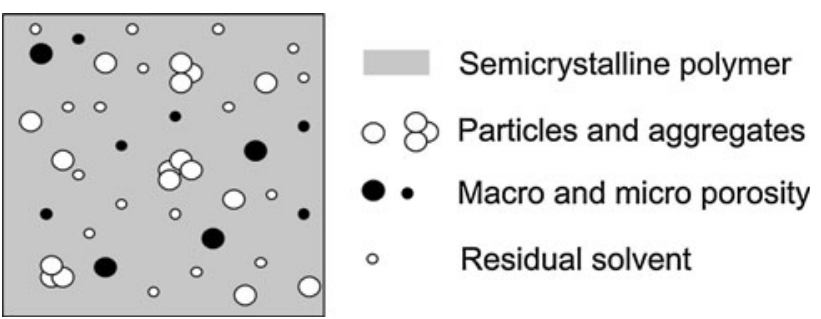

Fig. 12 Model of the morphology of highly filled polymer/ceramic composites

It was also evident from the results reported above that the differences in the dispersion state of the $\mathrm{BaTiO}_{3}$ particles, as well as in the degree of crystallinity of the polymer matrix, depending on the powder characteristics and on the processing route, were reflected in differences in the mechanical, dielectric, and piezoelectric properties of the materials. The annealed solvent cast and compression molded P(VDF-TrFE) films showed a better-developed crystalline structure than the not annealed solvent cast films, resulting in lower $\tan \delta$ and higher modulus in the range of temperatures between 0 and $100{ }^{\circ} \mathrm{C}$. However, for the SCA composite films the inhomogeneity in particle dispersion caused a degradation of the mechanical properties with increasing $\mathrm{BaTiO}_{3}$ content. The dielectric and piezoelectric properties of compression molded films were also superior to those of solvent cast and annealed films. For CM composites the relative permittivity increased according to models and the $d_{33}$ increased linearly with $\mathrm{BaTiO}_{3}$ vol\%.

\section{Conclusions}

The morphology, structure, and properties of (0-3) piezoelectric $\mathrm{P}(\mathrm{VDF}-\mathrm{TrFE}) / \mathrm{BaTiO}_{3}$ composites were found to be highly dependent on the volume fraction of $\mathrm{BaTiO}_{3}$ particles and on the processing route. The compression molding step was found to give the best results for the mechanical, piezoelectric, and dielectric properties of highly filled composites when compared to only solvent casting and annealing, with the CM composites containing $60 \% \mathrm{BaTiO}_{3}$ showing a sevenfold increase of the storage modulus, a high permittivity up to 120 , and a $d_{33}$ up to $32 \mathrm{pC} / \mathrm{N}$. The improvement in properties due to compression molding was mainly attributed to the reduction of inhomogeneities and porosity. Other methods to improve the compatibility between the hydrophilic $\mathrm{BaTiO}_{3}$ particles and the hydrophobic P(VDF-TrFE) matrix may lead to an improvement in the quality and properties of the solvent cast films. The observed reduction of $d_{33}$ with aging time was found to be reversible, and was attributed to the viscoelastic behavior of the polymer. For practical applications the aging phenomenon will need to be further understood and drastically reduced. Work aiming at addressing these two points is currently ongoing, exploring the effects of the surface modification of the $\mathrm{BaTiO}_{3}$ particles with silanes and the effect of aging on the morphology and structure of $\mathrm{P}(\mathrm{VDF}-\mathrm{TrFE}) / \mathrm{BaTiO}_{3}$ composites.

Acknowledgements The authors would like to thank the Swiss Federal Office of Energy (OFEN) and Swiss National Science Foundation (SNF) for funding, Solvay Solexis SpA for kindly providing $\mathrm{P}(\mathrm{VDF}-\mathrm{TrFE})$ and for fruitful discussion, Li Jin for preparing the in house made $\mathrm{BaTiO}_{3}$ powder and Arthur Aebersold for technical support. The Laboratory of Powder Technology (LTP) and the Interdisciplinary Centre for Electron Microscopy (CIME) at EPFL are also acknowledged for support and access to their equipment.

\section{References}

1. Dias CJ, Dasgupta DK (1994) In: Ferroelectric polymers and ceramic-polymer composites. Key engineering materials, vol 92-9. Trans Tech Publications, Clausthal Zellerfe, p 217 
2. Akdogan EK, Allahverdi M, Safari A (2005) IEEE Trans Ultrason Ferroelectr Freq Control 52(5):746

3. Newnham RE, Skinner DP, Cross LE (1978) Mater Res Bull 13(5):525

4. Han KH, Safari A, Riman RE (1991) J Am Ceram Soc 74(7): 1699

5. Sa-Gong C, Safari A, Newnham RE (1986) In: IEEE proceedings of the 6th international symposium on applications of ferroelectrics, Bethlehem, p 281. doi:10.1109/ISAF.1986.201142

6. Yamamoto T, Urabe K, Banno H (1993) Jpn J Appl Phys 32:4272

7. Chau KH, Wong YW, Shin FG (2007) Appl Phys Lett 91(25):3. doi:10.1063/1.2827571

8. Capsal JF, Dantras E, Dandurand J, Lacabanne C (2006) J NonCryst Solids 353:4437. doi:10.1016/j.jnoncrysol.2007.01.097

9. Petchsuk A, Supmak W, Thanaboonsombut A (2009) J Appl Polym Sci 114(2):1048. doi:10.1002/app.30636

10. Ploss B, Ng W-Y, Chan HL-W, Ploss B, Choy C-L (2001) Compos Sci Technol 61(7):957

11. Ploss B, Shin FG, Chan HLW, Choy CL (2000) IEEE Trans Dielectr Electr Insul 7(4):517

12. Chan HLW, Ng PKL, Choy CL (1999) Appl Phys Lett 74(20):3029

13. Zeng R, Kwok KW, Chan HLW, Choy CL (2002) J Appl Phys 92(5):2674. doi:10.1063/1.1497699

14. Helke G, Lubitz K (2008) In: Heywang W, Lubitz K, Wersing W (eds) Piezoelectricity. Evolution and future of a technology. Springer series in materials science, vol 114. Springer, Berlin, p 89

15. Chen XD, Yang DB, Jiang YD, Wu ZM, Li D, Gou FJ, Yang JD (1998) Sens Actuators, A 65(2-3):194

16. Yao JL, Xiong CX, Dong LJ, Chen C, Lei YA, Chen L, Li R, Zhu QM, Liu XF (2009) J Mater Chem 19(18):2817. doi:10.1039/ b819910h

17. Kerimov MK, Kurbanov MA, Musaeva SN, Geidarov GM, Aliev GG (2009) Tech Phys Lett 35(2):166. doi:10.1134/s10637 85009020205

18. Panda PK (2009) J Mater Sci 44(19):5049. doi:10.1007/s10853009-3643-0

19. Karaki T, Yan K, Miyamoto T, Adachi M (2007) Jpn J Appl Phys 46(4):L97. doi:10.1143/jjap.46.197

20. Xu JW, Moon KS, Pramanik P, Bhattacharya S, Wong CP (2007) IEEE Trans Compon Packag Technol 30(2):248. doi:10.1109/ tcapt.2007.898352

21. Dang ZM, Wang HY, Xu HP (2006) Appl Phys Lett 89(11):3. doi:10.1063/1.2338529

22. Dang ZM, Xu HP, Wang HY (2007) Appl Phys Lett 90(1):3. doi: $10.1063 / 1.2393150$

23. Dang Z-M, Yu Y-F, Xu H-P, Bai J (2008) Compos Sci Technol 68(1): 171

24. Kim P, Doss NM, Tillotson JP, Hotchkiss PJ, Pan MJ, Marder SR, Li JY, Calame JP, Perry JW (2009) ACS Nano 3(9):2581. doi:10.1021/nn9006412

25. Luo XT, Chen LF, Chen XJ, Huang QJ (2004) J Mater Sci Technol 20(4):441

26. Chan HLW, Cheung MC, Choy CL (1999) Ferroelectrics 224(1-4):541

27. Patil R, Ashwin A, Radhakrishnan S (2007) Sens Actuators, A 138(2):361. doi:10.1016/j.sna.2007.05.025

28. Muralidhar C, Pillai PKC (1986) IEEE Trans Electr Insul 21(3): 501

29. Venkatragavaraj E, Satish B, Vinod PR, Vijaya MS (2001) J Phys D-Appl Phys 34(4):487
30. Dietze M, Krause J, Solterbeck CH, Es-Souni M (2007) J Appl Phys 101: 054113. doi:10.1063/1.2653978

31. Mao YP, Mao SY, Ye ZG, Xie ZX, Zheng LS (2010) J Appl Phys 108: 014102. doi: $10.1063 / 1.3443582$

32. Lam KH, Wang XX, Chan HLW (2005) Compos A Appl Sci Manuf 36(11):1595. doi:10.1016/j.compositesa.2005.03.007

33. Dang ZM, Yuan JK, Zha JW, Zhou T, Li ST, Hu GH (2012) Prog Mater Sci 57(4):660

34. Chanmal CV, Jog JP (2008) Express Polym Lett 2(4):294. doi: 10.3144/expresspolymlett.2008.35

35. Cheung MC, Chan HLW, Choy CL (2001) Ferroelectrics 264(1-4):1721

36. Dang ZM, Zheng Y, Xu HP (2008) J Appl Polym Sci 110(6):3473. doi:10.1002/app.28856

37. Gregorio R, Cestari M, Bernardino FE (1996) J Mater Sci 31(11):2925. doi: $10.1007 / \mathrm{bf00356003}$

38. Iijima M, Sato N, Wuled Lenggoro I, Kamiya H (2009) Colloids Surf A 352(1-3):88

39. Muralidhar C, Pillai PKC (1989) Ferroelectrics 89:17

40. Muralidhar C, Pillai PKC (1987) J Mater Sci Lett 6(3):346

41. Patsidis A, Psarras GC (2008) Express Polym Lett 2(10):718. doi: 10.3144/expresspolymlett.2008.85

42. Ramajo L, Castro MS, Reboredo MM (2007) Compos A Appl Sci Manuf 38(8): 1852

43. Ramajo L, Reboredo M, Castro M (2005) Compos A Appl Sci Manuf 36(9):1267. doi:10.1016/j.compositesa.2005.01.026

44. Kar-Gupta R, Venkatesh TA (2008) Acta Mater 56(15):3810

45. Chandradass J, Bae DS (2008) Mater Manuf Processes 23(2):117. doi: 10.1080/10426910701774320

46. Marra SP, Ramesh KT, Douglas AS (1999) The mechanical properties of lead-titanate/polymer 0-3 composites. Compos Sci Technol 59(14):2163

47. Marra SP, Ramesh KT, Douglas AS (1999) Smart Mater Struct $8(1): 57$

48. Dutta PK, Asiaie R, Akbar SA, Zhu W (1994) Chem Mater 6(9):1542. doi:10.1021/cm00045a011

49. Baeten F, Derks B, Coppens W, van Kleef E (2006) J Eur Ceram Soc 26(4-5):589

50. Lovinger AJ, Furukawa T, Davis GT, Broadhurst MG (1983) Polymer 24(10): 1225

51. Kodama H, Takahashi Y, Furukawa T (1997) Ferroelectrics 203(1):433

52. Gregorio RJ, Botta MM (1998) J Polym Sci Part B 36(3):403

53. Simoes R, Rodriguez-Perez M, De Saja J, Constantino C (2009) Polym Eng Sci 49(11):2150. doi:10.1002/pen.21455

54. Yagi T, Tatemoto M, Sako J (1980) Polym J 12(4):209

55. Sencadas V, Lanceros-Méndez S, Mano JF (2006) J Non-Cryst Solids 352(50-51):5376

56. Zhang SH, Klein RJ, Ren KL, Chu BJ, Zhang X, Runt J, Zhang QM (2006) J Mater Sci 41(1):271. doi:10.1007/s10853-0066081-2

57. Hashin Z, Shtrikman S (1963) J Mech Phys Solids 11(2):127

58. Dent AC, Bowen CR, Stevens R, Cain MG, Stewart M (2007) J Eur Ceram Soc 27(13-15):3739. doi:10.1016/j.jeurceramsoc.2007. 02.031

59. Tessier-Doyen N, Glandus JC, Huger M (2007) J Mater Sci 42(14):5826. doi:10.1007/s10853-006-1386-8

60. Jayasundere N, Smith BV (1993) J Appl Phys 73(5):2462

61. Kerner EH (1956) Proc Phys Soc B 69(8):802 